\title{
TEACHERS’ PROBLEMS IN TEACHING MATHEMATICS USING MOTHER TONGUE IN A DISTRICT OF THE PHILIPPINES
}

\author{
Baquiller $\mathrm{GE}^{1 *}$ and Abellon Jr. $\mathrm{W}^{2}$ \\ ${ }^{1}$ Jose Rizal Memorial State University \\ ${ }^{2}$ Depament of Education, Philippines
}

\begin{abstract}
The transition of teaching Mathematics from English language to Mother tongue-based in primary grades has brought challenges and problems to teachers concerned. This paper attempts to determine those problems encountered by these teachers teaching Mathematics using Mother Tongue and the possible recourses they employed to address those problems. The study employed the descriptive- survey method of research using a questionnaire, purposively distributed to seven principals and thirty-three teachers who are identified respondents. Weighted mean and ranking system were utilized as measures to find out the prevalent problem, its recourses and how frequent they used the recourses. Based on the data gathered and analyzed, it was found out that language is the most prevalent problem in teaching Mathematics using mother tongue of which, insufficient translation from English term to mother tongue ranks on top. Whereas, in the area of instruction, content delivery using MT as medium for instruction is the major problem, while for teaching materials, the incomplete or delayed arrival of instructional material prevailed the most. The result further revealed that the identified problems in terms of language, teaching instruction and teaching material are mostly described as serious problem. To address the problem with regards to language; the teachers used other MT terms that fits the unfamiliar MT term, allowing pupils to use their own preferred term and remain to use English translation/ term. While for instruction; teachers use translation, drills, code switching, and pictures, whereas for teaching materials, teachers used school funds for material production, utilize local magazines as supplement, share resources to other grade level and borrow materials from other schools. All these recourses were all oftentimes applied/used. From the results, it is recommended that becoming teachers should be equipped with knowledge on teaching MTB-MLE and newly-hired teachers should attend seminars and trainings regarding such implementation. Principals or school heads should find measures for speedy delivery of learning materials
\end{abstract}

Keywords: Teaching Mathematics, Problems on Language, Materials and Instruction, Recourses for Teaching MTB-MLE

\section{Introduction}

Language plays an important role in understanding Mathematical concepts. Familiarity or lack of it may determine the failures and success. Human beings since in the history use language to communicate, resolve conflicts and solve numerical problems. It is one attribute that sets humans apart from all other creatures and binds human together across all geographic barriers. Language serves as the bridge to understanding. Thus, even learning of mathematics requires linguistic skills. In 
the modern approach of teaching mathematics, research was made and concluded that the use of the mother tongue help learners to achieve high grades. It was already revealed that teaching using the mother tongue in the early grades enhances children's ability to learn better compared to the use of a second or foreign language (UNESCO, 2003; Skutnabb-Kangas, 2003 as cited by Rai, et al., 2011). It has also been reported that if children are taught in languages which are different from their home language or mother tongue, they drop out from school, have low academic performance, and repeat classes due to a high failure rate. This state of affairs is still persistent in Nepal (Yadava, 2007; Awasthi, 2004 as cited by Rai, et al., 2011).

While in the Philippines, one of the latest developments in the its educational system is the Mother Tongue - Based Multilingual Education (MTB-MLE). MTB-MLE which refers to the use of students' mother tongue and two or more additional languages as Languages of Instruction (LoI) in school. In other contexts, the term is used to describe bilingual education across multiple language communities - each community using its own mother tongue aside from the official school language of instruction. In South Asia multilingual education usually follows the first definition, learning and using multiple languages in school. In some countries, MTB-MLE includes four languages-the students' mother tongue or first language, a regional language, the national language and an international language (Malone, 2007). According to the official language policy of the 1987 Educational Act (revised in 2004), children in Grades 1 - 3 were to be instructed in their first language, while those in Grade 4 onwards are set to be instructed using a second language (L2), which is English. This language policy can be identified as a possible model for bilingual education (Borch \& Tombari, 1997 as cited by Ndamba, 2008).

Since the start of MTB-MLE policy, several studies were conducted regarding its implementation. According to Tundag, et al. (2020), translation of mathematical concepts or language in the mother tongue had been a serious problem, while giving of exercises and activities were regarded as moderate problem in a certain school in Dumaguete, Philippines. Similar challenges had been claimed by the teachers in another school in the same country of which according to Lartec, et al. (2014), absence of books written in mother tongue, lack of vocabulary and lack of teacher's trainings were among the top problems.

Indeed, in the Philippine setting, the use of mother tongue seems to be the second language for the learners, because they are using English mathematical terms at home instead of their native tongues. And many of the students lost their interest due to language confusion. Transferee pupils (with different L1) have difficulty understanding the lessons and do not participate, (Casalan et. al., 2016).

For and in consideration of the aforementioned and due to limited research conducted locally, the researchers would like to find out what are the problems these teachers in Mathematics had encountered using the MTB-MLE and how they address these problems in its own locale.

\section{Objectives of the Study}

The study aimed to determine the problem and teacher's recourse in teaching Elementary Mathematics using mother tongue in a certain district of the Philippines involving seven elementary schools. Specifically, it is directed to identify the prevalent problems encountered by the teachers in teaching Mathematics using mother tongue, as well as determine its degree of seriousness of those 
problems experienced. It was also directed to find out the recourses employed by the teachers to address the problems as indicated along language, teaching instruction and teaching material.

\section{Research Methodology}

This study is a quantitative type utilizing the descriptive survey method using a researcher-made instrument to seek the teacher recourse in teaching mathematics using mother tongue. It was conducted at seven (7) selected elementary schools in a certain district of the Philippines.The questionnaire -checklist was divided into two parts. The first part of the questionnaire are the item statements stating the identified problems in terms of a) language, b) teaching instruction \& c) teaching material while the second part are the recourses employed by the respondents in addressing the problem.

Prior to the conduct of the questionnaire-checklist, the researchers prepared a permission letter addressed to different persons concerned. The researchers personally distributed the questionnaires and explained properly the purpose of the study and read the instruction orally. Respondents were given enough time to answer and questionnaires were collected afterwards. The data obtained were tabulated in tables and interpreted. In order to answer the specific question asked in the study, frequency count, ranking system and weighted mean were used.

\section{Results and Discussion}

Table 1. Prevalent Problems in Teaching Mathematics Using Mother Tongue

\begin{tabular}{lcccccc} 
& Teachers & \multicolumn{3}{c}{ Principals } & \multicolumn{2}{c}{ Overall } \\
& $\mathrm{x}$ & Rank & $\mathrm{x}$ & Rank & $\mathrm{x}$ & Rank \\
\hline Language & 3.76 & 1 & 3.70 & 2 & 3.73 & 1 \\
\hline Teaching Instruction & 3.75 & 2 & 3.66 & 3 & 3.71 & 3 \\
\hline Teaching Materials & 3.5 & 3 & 3.82 & 1 & 3.66 & 2 \\
\hline
\end{tabular}

One of the important directions of the study is to find out the most prevailing problems in teaching Mathematics using mother-tongue. As gleaned from the above table, data revealed that language ranks on top among the problems in teaching Mathematics using Mother Tongue with a GWM of 3.73; followed by teaching Material and lastly teaching Instruction with a GWM of 3.68 and 3.66 respectively.

This is in consonance with the findings of (Mahboob and Cruz 2013) that one of the major problems in the Philippines especially in the implementation of the mother tongue instruction is that we never actually use our local language in counting numbers, instead we submit too much to the foreign language. They further affirmed that the Philippines regard English as the premium language with Filipino and other local languages relegated to the background. 
Table 2. Degree of Seriousness on the Problems Encountered in Terms of Language

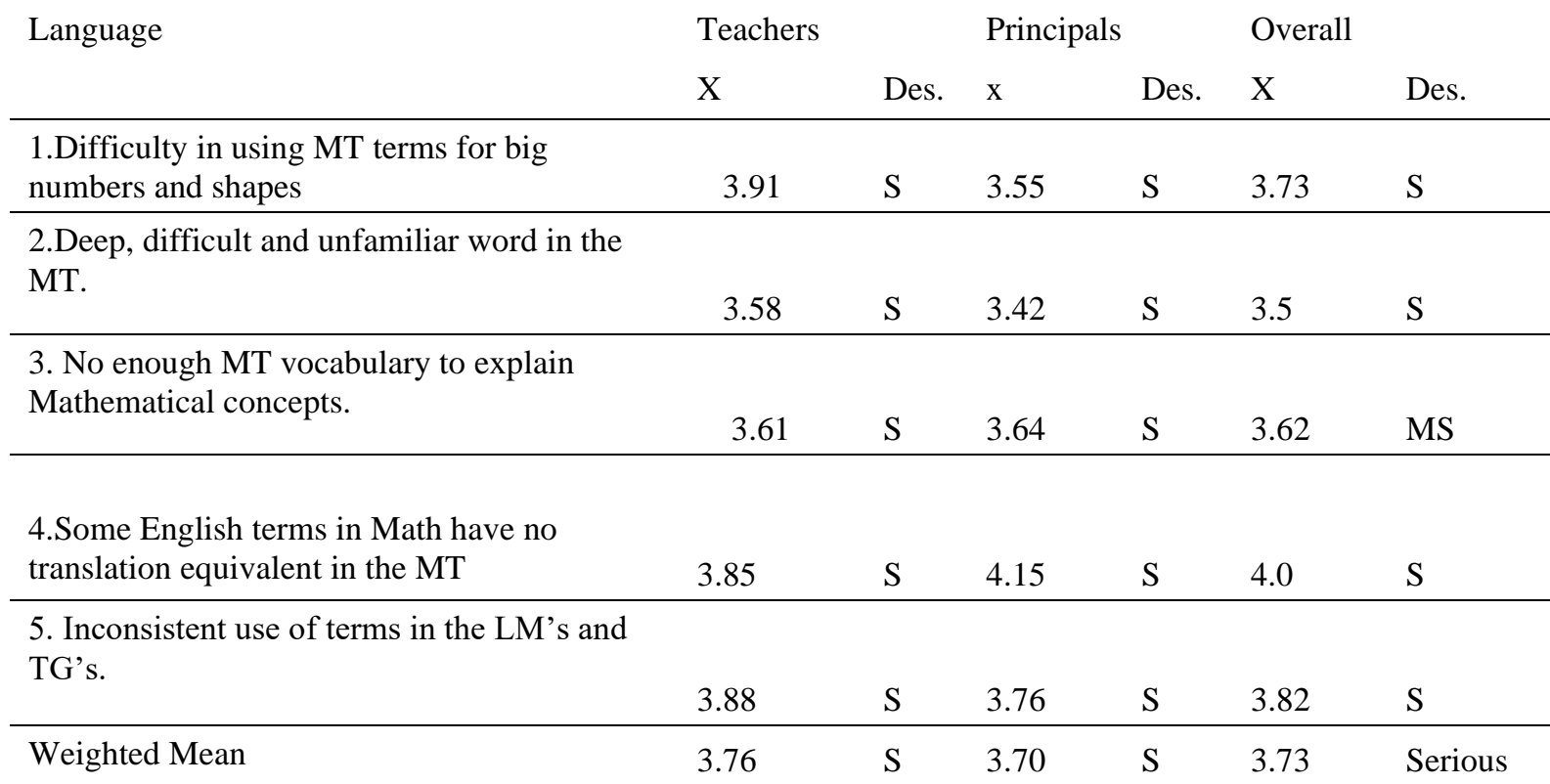

Findings about the degree of seriousness of each specific parameter that fall under language as a problem are then indicated. All of the item statements, except for insufficient MT vocabulary to explain mathematical concept which is described as moderately serious, are perceived as serious problem. However, the highest degree is the statement that "some English terms in Math have no translation equivalent in the MT. This implies that the respondents have much problem on how to translate Mathematics terms from English language to mother or native tongue.

This is possibly attributed with the idea that Filipinos are influenced much on the Western language where the use of MT for mathematical operations declines throughout the generations.

In like manner, the MT used in some part of Zamboanga peninsula is the regional language of folks living in Cebu. According to Dr. Yolanda S. Quijano, Director of the DepEd Bureau of Elementary Education that Cebuanos prefer to use English than the mother tongue. The teachers also realized that there are limitations of the applicability of the MTB-MLE as they noticed that not all concepts of mathematics and the natural sciences could be taught through MTB-MLE. (Medilo 2017) and they lack vocabulary to be used in translating an English and Filipino word.

Table 3. Degree of Seriousness on the Problems Encountered by Teachers in Terms of Teaching Instruction in Kalawit District

\begin{tabular}{|c|c|c|c|c|c|c|}
\hline \multirow[t]{2}{*}{ Teaching Instruction } & \multicolumn{2}{|c|}{ Teachers } & \multicolumn{2}{|l|}{ Principals } & \multicolumn{2}{|c|}{ Overall } \\
\hline & $\mathrm{x}$ & Des. & $\mathrm{X}$ & Des. & $\mathrm{x}$ & Des. \\
\hline \multicolumn{7}{|c|}{$\begin{array}{l}\text { 1. Pupils' adjustment of using MT } \\
\text { in participating class discussion } \\
\text { instead of English }\end{array}$} \\
\hline & 3.76 & $S$ & 3.58 & $S$ & 3.67 & S \\
\hline $\begin{array}{l}\text { 2. Delivery of lesson } \\
\text { medium for instructio } \\
\text { Math. }\end{array}$ & 3.94 & $S$ & 3.88 & $\mathrm{~S}$ & 3.91 & $\mathrm{~S}$ \\
\hline
\end{tabular}


3. Pupil's understanding of the lesson since the MOI is unfamiliar

3.97

S

3.81

S

3.89

S

4. Teaching strategies of teachers in discussing the lesson using MT.

3.27
$\mathrm{S}$ 3.33 MS 3.33 MS

5. Difficulty in constructing questions for quizzes and exams of the students.

\begin{tabular}{lllllll} 
& 3.79 & $S$ & 3.7 & $S$ & 3.75 & $S$ \\
\hline Weighted Mean & 3.75 & S & 3.66 & S & 3.71 & Serious
\end{tabular}

One aspect identified as a serious problem on the implementation of MTB-MLE is teaching instruction. Based on the data gathered, among the constructs presented, only teaching strategies is described to be moderately serious, but the rest are already described as a serious problem of which delivery of lesson ranks on top.

Meaningful learning will only take place if the language of instruction brings meaningful and authentic communication between teachers and learners. In the study of (Espada et.al 2017), it was reported that the children replied in English whenever they were talked to in the mother tongue. They often asked for the English translation of unfamiliar words. Parents shared that their children can't understand the mother tongue used in LMs because his first language is English.

Table 4: Degree of Seriousness on the Problems Encountered by Teachers in Terms of Teaching Material

\begin{tabular}{|c|c|c|c|c|c|c|}
\hline \multirow[t]{2}{*}{ Teaching Materials } & \multicolumn{2}{|c|}{ Teachers } & \multicolumn{2}{|c|}{ Principals } & \multicolumn{2}{|c|}{ Overall } \\
\hline & $\mathrm{x}$ & Des. & $\mathrm{x}$ & Des. & $\mathrm{x}$ & Des. \\
\hline $\begin{array}{l}\text { 1. Lack of TG's and LM's and other } \\
\text { resource in the MT. }\end{array}$ & 3.12 & MS & 3.61 & $\mathrm{~S}$ & 3.37 & $\mathrm{~S}$ \\
\hline $\begin{array}{l}\text { 2. Insufficient financial support for } \\
\text { materials. }\end{array}$ & 3.55 & $\mathrm{~S}$ & 3.91 & $\mathrm{~S}$ & 3.73 & $\mathrm{~S}$ \\
\hline \multicolumn{7}{|l|}{$\begin{array}{l}\text { 3. Incomplete or delayed delivery of } \\
\text { Instructional Material. }\end{array}$} \\
\hline & 3.98 & $S$ & 4.09 & $S$ & 4.03 & $S$ \\
\hline \multicolumn{7}{|l|}{$\begin{array}{l}\text { 4. Mismatch between the MT used as } \\
\text { MOI and the MT in which the LM's } \\
\text { and TG's were written }\end{array}$} \\
\hline & 3.33 & MS & 3.55 & $S$ & 3.44 & MS \\
\hline \multicolumn{7}{|l|}{ 5. Non- contextualization of LM's } \\
\hline & 3.52 & $\mathrm{~S}$ & 3.94 & $\mathrm{~S}$ & 3.73 & $\mathrm{~S}$ \\
\hline Weighted Mean & 3.5 & $S$ & 3.82 & $\mathrm{~S}$ & 3.66 & Seric \\
\hline
\end{tabular}


The preceding tabular presentation contains the problems of Mathematics teachers in terms of teaching materials which revealed an over-all description of serious problem. Despite a similarity of the parameters' descriptive rating, the highest mean of 4.03 is given for incomplete or delayed delivery of instructional material.

Per interview and casual conduct of inquiry, this aspect appears to be the most prevailing serious problem since it affects the delivery of instruction and that it is beyond the capacity of teachers and principals since IM's are still from the head office (Manila) which is then transported to the region and eventually to the respective division/districts.

In the study of (Malone, 2012) as cited by (Kadel, 2012), they mentioned several challenges in planning, implementing and sustaining an excellent mother tongue-based education. These are absence of concrete orthographies, shortage of mother tongue teaching materials, scarcity of written literature, and deficiency of curriculum and instructional materials. Although they are all MT (Binisaya) speakers, they had voiced their feelings of certainty and expressed fears about the scarcity of MTB-MLE instructional materials available in their school. They expressed the need for more MT materials, more training and more help in developing materials to bridge the MT to L2 or L3 language.

Table 5: Recourses on the Problems Encountered by the Teacher's in Teaching Mathematics Using Mother Tongue

\begin{tabular}{|l|l|l|}
\hline Teachers Problems & Recourses Employed & Frequency of Used \\
\hline Language & $\begin{array}{l}\text { In terms of problem in language, the teachers make } \\
\text { used of English translation when no terms are } \\
\text { available in mother tongue, used of other phrases or } \\
\text { words that fit unfamiliar MT, used of pictures that } \\
\text { relates to MT terms, applications of different } \\
\text { languages and utilizing the preferred MT of the } \\
\text { majority }\end{array}$ & $\begin{array}{l}\text { All the recourses are } \\
\text { oftentimes applied }\end{array}$ \\
\hline Teaching Instruction & $\begin{array}{l}\text { Teachers used translation to deepen explanation, } \\
\text { used of code-switching to avoid profound MT } \\
\text { vocabulary, used of drills on MT terms of colors, } \\
\text { shape, and numbers, ETC., used of pictures and } \\
\text { students used code - switching to express answer. }\end{array}$ & $\begin{array}{l}\text { All recourses are } \\
\text { oftentimes applied }\end{array}$ \\
\hline Teaching Materials & $\begin{array}{l}\text { Use of school funds (MOOE) for the material } \\
\text { production. Teachers used local magazines as } \\
\text { additional MT resource material. Teachers sharing } \\
\text { a pool of resources in the same grade level. } \\
\text { Teacher's continuous production of IM's. } \\
\text { Borrowing from other schools with more resources. }\end{array}$ & $\begin{array}{l}\text { All the recourses are } \\
\text { oftentimes applied }\end{array}$ \\
\hline
\end{tabular}

\section{Conclusion}

On the light of research findings, it is concluded that the prevalent problem in teaching Mathematics using Mother Tongue in a district of the Philippine is language and that degree of seriousness of the indicators presented in all the identified problems are all experienced seriously by the concerned teachers. Thus, recourses are initially performed to address the problems. 


\section{Recommendations}

Based on the findings of the study, it is hereby recommended that more Mathematical terms should be translated into mother tongue or native language and that faculty members handling Mathematics subject should be sent to seminars and trainings concerning MTB-MLE instruction so that their delivery of the subject will be improved. Parents should teach their children starting from an earliest age about the Mother Tongue of the community. Further, principal or school heads should take extra measures for the speedy delivery of learning materials so that the same will reach in the respective locality the soonest possible time. It is also good to conduct another study to verify the results.

\section{References}

Cruz, N. (2015). The Implementation of The Mother Tongue-Based Multilingual Education In Grade I In The Public Elementary Schools In Pangasinan I

Espada J. Mocorro R. (2017) Challenges In The Implementation Of The Mother Tongue-Based Multilingual Education Program: A Case Study.

Lartec, J. Belisario, A. Bendanillo, J. Binas-o, H. Bucang, N. and Cammagay, J.L.(2014) Strategies and Problems Encountered by Teachers in Implementing Mother Tongue - Based Instruction in a Multilingual Classroom. The IAFOR Journal of Language Learning, Vol. I- Issue I. https://iafor.org/archives/journals/10.22492.ijll.1.1.04pdf

Mahboob, Ahmar (2013). Asian Journal of English Language Studies. The Official Journal of the UST Department of English. Retrieved from http://departmentofenglish.ust.edu.ph/

Malone, S. (2007). Mother tongue-based multilingual education: Implications for education policy. A paper presented at the Seminar on Education Policy and the Right to Education: Towards More Equitable Outcomes for South Asia's Children, Kathmandu, September 17-20, 2007. Retrieved from https://www.sil.org/sites/default/files/files/mtbmle_implications_for_policy.pdf

Matang, R. A. (2003). The cultural context of mathematics learning and thinking in Papua New Guinea. Directions: Journal of Educational Studies, University of South Pacific, 24(1), 27-37. Available: http://www.uog.ac.pg/glec/Key/key.htm

Medilo, C. G. (2016). The experience of mother tongue-based multilingual education teachers in Southern Leyte, Philippines. International Forum, 19(2), 64-79. Retrieved from http://ojs.aiias.edu/index.php/ojs/article/view/186/185

Metila, R. Pradilla, L. \& Williams, A. (2016). Investigating best practice in Mother Tongue-Based Multilingual Education (MTB-MLE) in the Philippines, Phase 2 progress report: Patterns of challenges and strategies in the implementation of mother tongue as medium of instruction in the early years: A nationwide study.

Ndamba, G. T. (2008) Mother tongue usage in learning: An examination of language preferences in Zimbabwe. Great Zimbabwe University

Quijano, Y.S. (2010), "MLE in the Philippines: History and Possibilities", Retrieved from http://docs.google.com/present/view?id=dd7bqfr8_17ctks8vg3

Rai, V., Rai, M., Phyak, P., Rai, N. (2011). Multilingual education in Nepal: Hearsay and reality? Kathmandu: United Nations Educational, Scientific and Cultural Organization Office (UNESCO)

Tundag, S., Cristina Calisang, Sheena Mae Comighud, Roulette Cordevilla and Maria Chona Z. Futalan.(2020) Problems Encountered by the Grade 2 Teachers in the Division of Dumaguete City in Teaching Mathematics Using Mother Tongue: A Basis For An Action Plan. DOI 10.5281/ zenodo. 3976882 